\title{
Doctor Érix Emilio Bozón Martínez, un pionero de la nutrición artificial en Colombia
}

\author{
Dr. Érix Emilio Bozón Martínez, \\ pioneer of artificial nutrition in Colombia
}

\author{
Diana Cárdenas ${ }^{1}$
}

https://doi.org/10.35454/rncm.v2n1.052

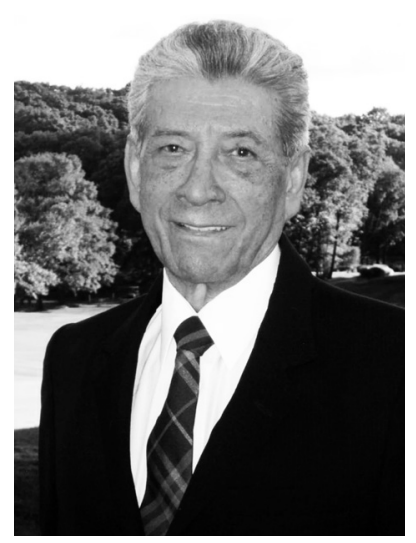

Dr. Érix Emilio Bozón Martínez, 1934-2018.
El 25 de octubre de 2018 el país pierde a un maestro y pionero de la nutrición artificial. El Dr. Bozón falleció en la ciudad de Bogotá después de que su cuerpo y su alma lucharan durante varios años para ganarle la batalla a la memoria.

Fue uno de los fundadores de la Escuela Colombiana de Medicina, Universidad El Bosque, donde se desempeñó como decano de la Facultad de Medicina, director de la División de Investigaciones, director de la División de Evaluación y Planeación, vicerrector académico y Rector. Ocupó diferentes cargos e importantes posiciones honoríficas: miembro de la Sociedad Colombiana de Historia de la Medicina, miembro de la junta directiva de la Federación Médica Colombiana y magistrado del Tribunal de Ética Médica, miembro honorario de la Asociación Colombiana de Nutrición Clínica quien seguirá rindiendo homenaje a su legado con el simposio anual que lleva su nombre.

Desde el año 1969, se desempeñó como profesor de cirugía de la Universidad Nacional (Hospital San Juan de Dios) y posteriormente como decano de la facultad de medicina de la misma universidad. En $1973 \mathrm{el}$ doctor Érix Bozón introdujo en Colombia la nutrición parenteral, la cual preparó y adaptó en los laboratorios de bioquímica y farmacia de la Universidad Nacional.
A partir de ese año, y gracias a su espíritu innovador los pacientes del Hospital San Juan de Dios de Bogotá se beneficiaron de lo que con tanto ímpetu él llamaba "la hiperalimentación” de los pacientes quirúrgicos.

Para quienes tuvimos el honor de tener al doctor Bozón como maestro lo recordaremos por el amor y la pasión con la que enseñaba la cirugía. Su legado en la medicina quedará por siempre grabado en la facultad de medicina de la Universidad El Bosque, y en particular, en el apoyo que le dio a la creación del grupo de Investigación en Nutrición, Genética y Metabolismo (IINGM) en el año 2009. En nombre de los investigadores del IINGM quiero hacer este homenaje al maestro y al ser humano que con alegría, pasión y amor a la medicina nos acompañó durante estos años. ¡Gracias Maestro!

"Hagamos una composición de lugar, espacio, modo y tiempo. Ubiquémonos, en un día de 1958... una tina colocada en la antesala de los vestuarios quirúrgicos.

Un cuerpo humano dentro de ella. Parecía muerto, pero no... estaba anestesiado y no sólo eso, cubierto e inmerso en hielo."

Recopilación histórica sobre la cirugía en el Hospital San Juan de Dios de Bogotá, «Oración Maestros de la Cirugía Colombiana»

E. Bozón Martínez, 1994

Oración Maestros de la Cirugía Colombiana, consultado el 1 de marzo 2019, disponible en: https://docplayer.es/34932961Oracion-maestros-de-la-cirugia-colombiana.html.

1 IINGM, Facultad de Medicina, Universidad El Bosque 